\title{
Birth weight and special educational needs: effects of an increase in the survival of very low birthweight infants in London
}

\author{
S T Kempley, F S Diffley, G Ruiz, D Lowe, B G Evans, H R Gamsu
}

\begin{abstract}
Objectives - To assess the contribution of children with different birth weights to special educational needs within a single health district, and to determine whether this pattern changed over the time when the survival of very low birthweight (VLBW) infants was increasing.

Setting - An inner London health district. Study design - A cohort of children born to local parents between January 1974 and December 1980 was selected from birth notifications, including only those infants who survived for more than one month. Community child health records were then inspected to identify children from the cohort who had been formally assessed for special educational needs before their 8th birthday. The risk of special educational needs was compared for the years 1974-77 and 1977-80 (the first and second halves of the period studied).
\end{abstract}

Subjects - The infant cohort consisted of 31846 children. Altogether $260(0 \cdot 8 \%)$ of these were later assessed formally.

Results - VLBW infants were 4.4 times more likely to be assessed than normal birthweight infants. Formal assessment within the district occurred in three of 68 VLBW infants from the first half of the period studied, and three of 120 from the second half.

Conclusion - Although VLBW infants are at higher risk, an increase in their survival was not associated with any increase in their contribution to the group with special educational needs within our district. Their contribution, as a group, to the total number of children with special educational needs is very small.

(f Epidemiol Community Health 1995;49:33-37)

The changing outlook for very low birthwight (VLBW) babies cared for in major neonatal units has been well documented. Over the past 20 years the use of more intensive methods of management, including respiratory support, has resulted in improved outcome. ${ }^{1}$ Nevertheless, a number of studies have shown that babies are at risk of neurodevelopmental problems which may result in later educational difficulties. $^{2}$

The 1981 Education $\mathrm{Act}^{3}$ requires that education authorities carry out formal assessments of children thought to have special educational needs, and allocate necessary additional resources to meet the needs of these children. A high rate of VLBW in inner city districts and an increasing number of VLBW survivors who require special education might impose an increased workload on already overstretched resources. This could occur if there was an increased survival of VLBW infants without any reduction in their morbidity.

Powell et al $l^{4}$ studied low birthweight survival and handicap within the Mersey health region over a three year period, and they made comparisons with geographically based studies of other areas. Their survival rates were higher and handicap rates lower than in earlier studies. This could be explained either by an improvement in outcome or simply by differences between regional populations. However, in his study of a single health district, Maddock ${ }^{5}$ claimed that mechanical ventilation of these babies was not of proved benefit, and suggested that increasing the survival of a group at high risk of handicap might increase the numbers of handicapped children within the local community. He went so far as to suggest that ventilation should be the subject of a controlled trial. The concern about the sequelae of intensive care has led some authors ${ }^{6}$ to include the price of special education of survivors when costing neonatal intensive care.

This study examines the contribution of VLBW infants to the group of children with special educational needs in Camberwell Health Authority, a health district in south east London, for births occurring over a seven year period from 1974-80. Scrutiny of hospital records suggested that this period coincided with a rapid rise in the numbers of VLBW survivors. Before 1974, birth notifications were collected by the London Boroughs of Southwark and Lambeth, but from 1974 these notifications were collected by an authority operating within the boundaries as currently designated. This date therefore determined the start of the study, and because we wished to include up to eight years from birth so that all major problems of educational importance could be recognised, 1980 was included as the last year of the study.

The requirement for special educational needs has been used as a measure of long term handicap. This measure has some advantages over diagnostic labels (such as cerebral palsy), as it is not biased towards selecting those cases who received hospital care in early life, and the requirement for special education is likely to reflect a child's overall level of functional dependence. However, definitions of special edu- 
cational needs may vary over time, and many different types of problem may be included in this category.

The provision of education within Camberwell Health District at the time of this study was the responsibility of the Inner London Education Authority (ILEA). From the late 1970 s, children with special educational needs have increasingly been integrated into normal schools; this was already taking place in our district before the process was accelerated by the 1981 Education Act. $^{3}$ It was therefore apparent that we would need to look beyond the population in designated special schools. If all children with special needs were to be included we would have to include those who were ascertained to be in need of special education but who were placed in normal schools and given extra help.

We have documented changes in the survival of VLBW babies over this time period, and attempted to examine whether this had any effect on the composition of the population with special educational needs.

\section{Methods}

SPECIAL EDUCATIONAL NEEDS GROUP

A formal "statementing" procedure, very similar to the "full assessment" procedure stipulated at present by the Education Act, had been used by the ILEA before 1981, and the community health department had been notified of "statemented" children as well as those admitted to special schools. Full assessments carried out under the provisions of the $E d u$ -

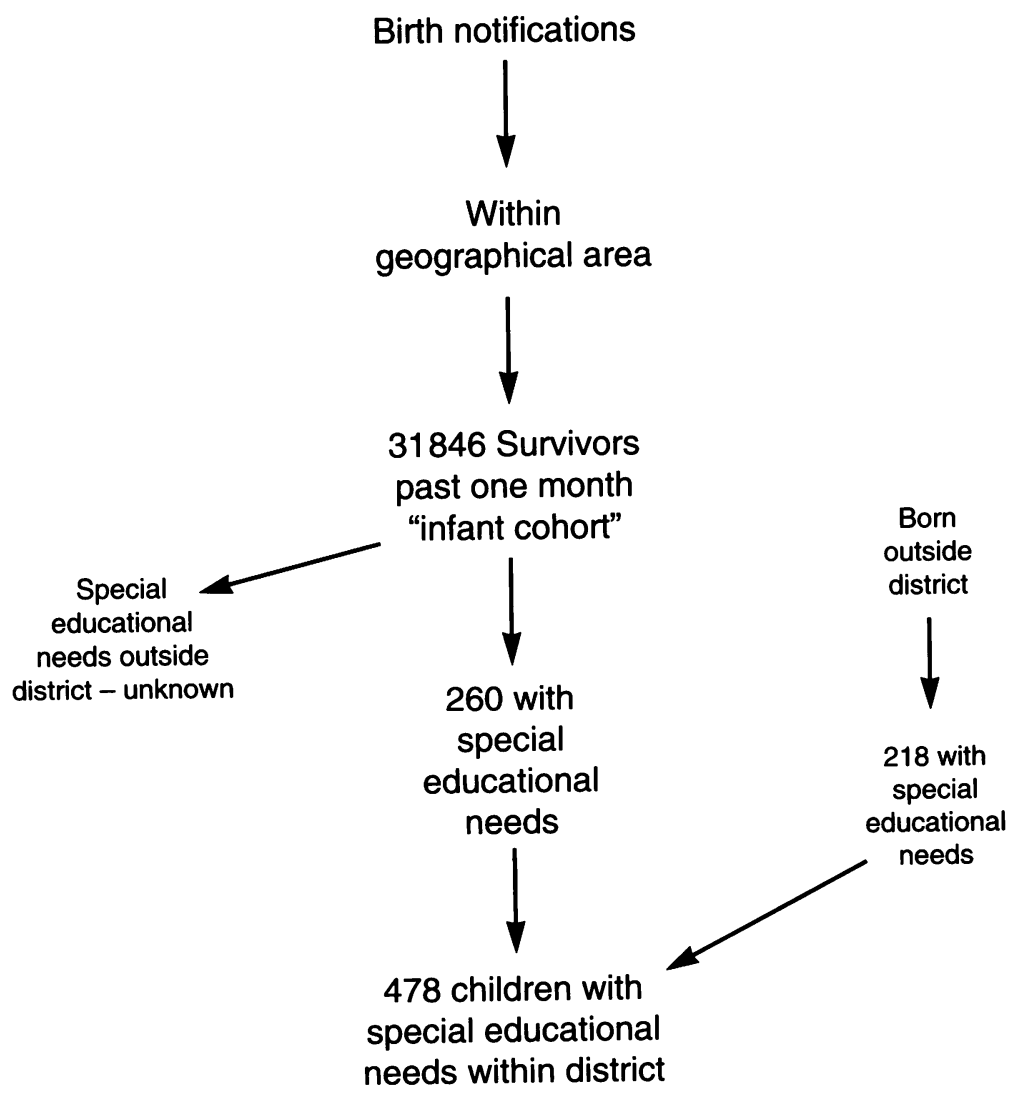

Figure 1. Study design. The study was limited to the infant cohort and those children from it who were assessed for special educational needs within the district. cation Act had also been notified to the community health department.

The records of the Camberwell Community Child Health Department were inspected to identify any children born between 1974 and 1980 who had either been admitted to a special school within the district or who had undergone formal assessment for special educational needs. This information was available even for those children who had moved out of the area after assessment, but was not available for those who moved before they were assessed. For the purposes of this study children were only included in the special educational needs (SEN) group if their admission to a special school or the request for assessment had occurred before their 8 th birthday.

To check that we were not missing any children who were in special schools without the knowledge of the Community Child Health Department, we carried out a pilot study in which we obtained a list of all those children in special schools who were born in 1979.

\section{INFANT COHORT}

All the original birth notification cards for Camberwell Health District were available for the period January 1974 to December 1980 . These cards were received by the authority for all births where (a) the mother was resident in the health district at the time of birth or (b) the birth occurred in a hospital within the district. All the cards included the mother's name and address, the baby's name, the date and time of birth, the baby's sex, and the birth weight. Other details such as mother and father's occupation and presence of congenital abnormalities were less likely to have been recorded.

The infant cohort consisted of all births occurring between 1 January 1974 and 31 December 1980 where the parental address was within a "SE" or "SW" London postal district. This geographical restriction was applied to exclude possible effects from increasing rates of in utero and ex utero perinatal transfer. Births were divided into four groups according to birth weight:

Group I (VLBW) $\leq 1500 \mathrm{~g}$

Group II 1501-2500 g

Group III $2501-4000 \mathrm{~g}$

Group IV $>4000 \mathrm{~g}$.

Since we were collecting this cohort primarily as a denominator against which we would contrast the later educational needs of survivors we excluded all stillbirths and neonatal deaths. However, for the VLBW births only, we listed separately live births who died in the first month.

MOBILITY AND BIRTH WEIGHT

The number of children from the infant cohort who were still resident in the district at the time of their 8th birthday remains unknown. To assess the residential stability of children from different birthweight groups we examined a sample from the infant cohort who were born in $1979-80$. 
Table 1 Numbers of infants in the infant cohort in each birthweight group, with the numbers who went on to be assessed for special educational needs (SEN). The relative risk of SEN (compared with group III) has been calculated for groups I, II $\mathcal{E} I V$ $(*=p<0.001)$.

\begin{tabular}{llrrl}
\hline Group & $\begin{array}{l}\text { Birth weight } \\
(g)\end{array}$ & $\begin{array}{l}\text { Infant } \\
\text { cohort }\end{array}$ & SEN & $\begin{array}{l}\text { Relative risk } \\
\text { of SEN }\end{array}$ \\
\hline I & $<1500$ & 188 & 6 & $4 \cdot 4^{*}$ \\
II & $1501-2500$ & 1982 & 34 & $2 \cdot 3^{*}$ \\
III & $2501-4000$ & 27700 & 203 & $1 \cdot 0$ \\
IV & $>4000$ & 1976 & 17 & $1 \cdot 2$ \\
Total & & 31846 & 260 & \\
\hline
\end{tabular}

We listed the names and dates of birth of the 50 VLBW survivors who were born between August 1979 and December 1980. Fifty survivors were also randomly selected from each of the other birthweight groups over the same time period. The names and dates of birth were then given to the local family practitioner committee who traced those children in each group who were still registered with a local general practitioner within our district.

\section{Results}

INFANT COHORT

The infant cohort consisted of 31846 survivors (fig 1). Of these, $0.59 \%$ were in birthweight group I (VLBW), $6 \cdot 2 \%$ in group II, $87 \%$ in group III, and $6 \cdot 2 \%$ in group IV (table 1 ).

There were no clear trends with time in the total number of infants in the infant cohort. The annual numbers ranged from 4183 in 1977 to 4857 in 1974 . No trends were seen in the numbers in groups II, III, and IV (fig 2).

The annual number of VLBW survivors increased from 11 in 1974 to 32 in 1980, whereas the number of neonatal deaths remained about the same (fig 3 ). The increases in the number of survivors was due to an increase in the total number of notifications and an increase in the survival rate. In the years with the greatest number of survivors, the mean birth weight of survivors was lower.

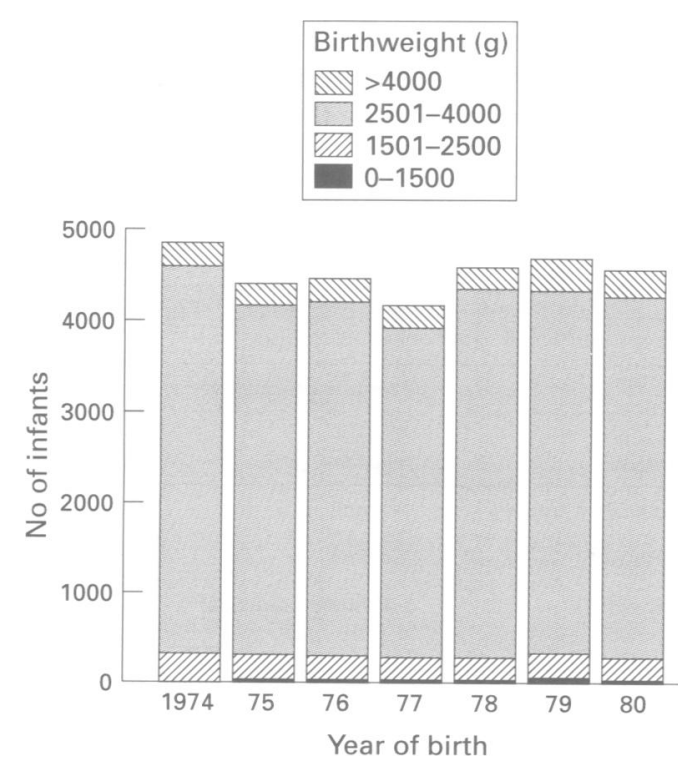

Figure 2. Annual numbers in the infant cohort and in each birthweight group.
MOBILITY AND RELIABILITY OF RECORDS

An unknown number of children from the infant cohort had left the district, and some of these children would have been assessed for SEN elsewhere without our knowledge. Residential stability was assessed in a sample of children born in 1979-80, and after eight years $43 \%$ of the sample were still registered with general practitioners within the district. There were no major differences in the mobility of the different birthweight groups, with 20 of 50 of those from group I still registered within the district after eight years, compared with 25 of 50 from group II, 19 of 50 from group III, and 22 of 50 from group IV. As a result of this degree of mobility, our estimates of the risk of SEN in each birthweight group will be roughly half of the true value, assuming the risks for those who stay and those who move are not too dissimilar. It is reasonable to calculate the relative risk of SEN in the different groups, making the assumption that mobility does not vary with birth weight (table 1 ).

In the pilot study of children born in 1979 , 43 out of 45 children in special schools were found to have been included in the community child health records; the two who were not included had been born elsewhere and thus were not named in the infant cohort. This confirmed that the central records were a reliable source to determine which children from the infant cohort were receiving special eduation.
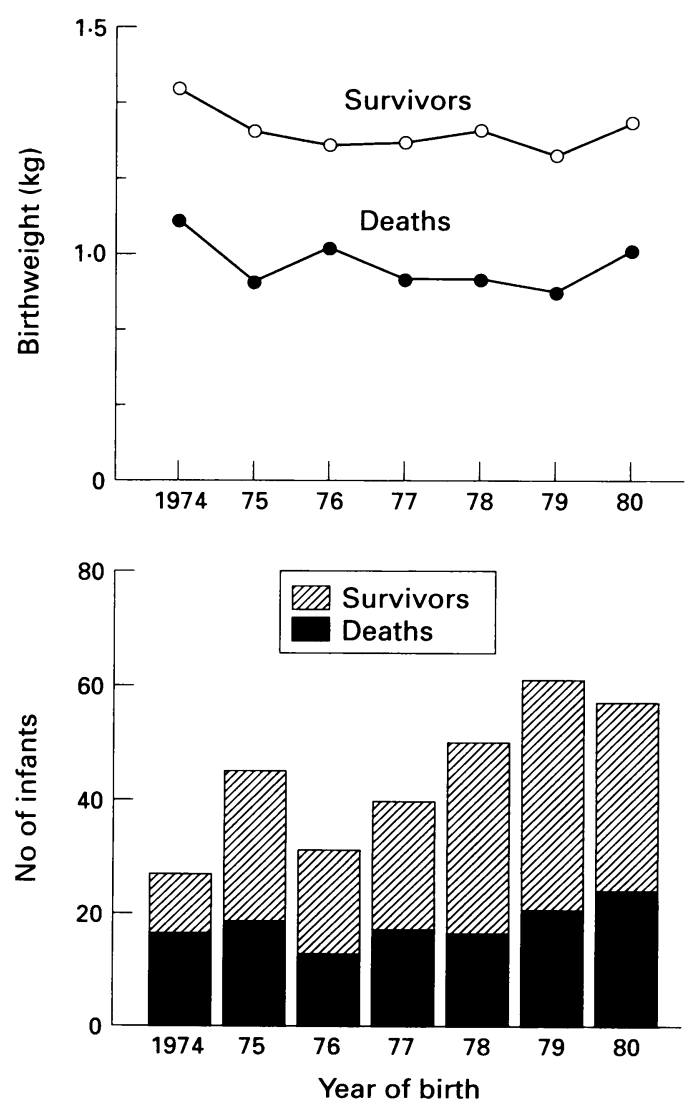

Figure 3. Annual numbers of very low birthweight (VLBW) survivors and VLBW neonatal deaths. The mean weight of VLBW survivors and VLBW neonatal deaths is shown for each year. 
Table 2 Numbers of survivors in the infant cohort for the first and second halves of the study (Fanuary 1974-Fune 1977, and fuly 1977-December 1980). The numbers from each period who went on to be assessed for special educational needs (SEN) is shown, with the percentage SEN rate.

\begin{tabular}{|c|c|c|c|c|c|c|}
\hline \multirow[t]{2}{*}{ Birth weight (g) } & \multicolumn{2}{|c|}{ No of survivors } & \multicolumn{2}{|c|}{ No with SEN } & \multicolumn{2}{|c|}{ Survivors with SEN (\%) } \\
\hline & $1974-77$ & $1977-80$ & $1974-77$ & $1977-80$ & $1974-77$ & $1977-80$ \\
\hline $\begin{array}{l}<1500 \\
1501-2500 \\
2501-4000 \\
>4000\end{array}$ & $\begin{array}{r}68 \\
997 \\
13790 \\
872\end{array}$ & $\begin{array}{r}120 \\
984 \\
13920 \\
1104\end{array}$ & $\begin{array}{r}3 \\
17 \\
89 \\
8\end{array}$ & $\begin{array}{r}3 \\
17 \\
114 \\
9\end{array}$ & $\begin{array}{l}4 \cdot 4 \\
1.7 \\
0 \cdot 7 \\
0 \cdot 9\end{array}$ & $\begin{array}{l}2 \cdot 5 \\
1 \cdot 7 \\
0 \cdot 8 \\
0 \cdot 8\end{array}$ \\
\hline
\end{tabular}

\section{SPECIAL EDUCATIONAL NEEDS}

Altogether 478 children born between $1974-80$ had been formally assessed for special educational needs within the district, but only 260 $(54 \%)$ were from the infant cohort (fig 1). Of these 260 , six $(2 \cdot 3 \%)$ were in birthweight group I, $34(13.1 \%)$ were in group II, $203(78 \%)$ were in group III, and $17(6.5 \%)$ were in group IV.

The relative risk for special educational needs of VLBW infants was $4 \cdot 4$ times that of infants weighing $2501-4000 \mathrm{~g}$ ( $\chi^{2}$ squared with Yates's correction $=12 \cdot 1, \mathrm{p}<\cdot 001)$. The relative risk that special education would be required was 2.4 for infants in group II $\left(\chi^{2}=21 \cdot 3, p<\cdot 001\right)$ and 1.2 for those in group IV $\left(\chi^{2}=0 \cdot 25, N S\right)$.

As there were very few infants with SEN from group I, we did not analyse annual trends for the risk of SEN, but instead compared the first and second halves of the period studied (table 2). There was very little difference in the numbers assessed for SEN between the first and second period, for all of the birthweight groups of the infant cohort.

Between the first and second half of the study the numbers of group I infants in the cohort increased from 68 to 120 . This meant that the risk of SEN for group I infants was actually slightly lower in the second half of the study, but because of the small numbers involved it is impossible to calculate the relative risk with any confidence. There were similar numbers of children in the first and second period in groups II, III, and IV, so that the risk of SEN was virtually unchanged for these groups.

Details of the neonatal course and educational problems of the six VLBW infants who were assessed for SEN are shown in table 3. Three had cerebral palsy (one from the first half, two from the second half of the study).
Of these, two attended schools for physically handicapped children, and one attended a mainstream school with part-time attendance at a school for the visually impaired. Two of the remaining children had a combination of language delay with mild to moderate learning difficulties, and one had attention deficit with patchy learning difficulties. One attended a school for children with moderate learning difficulties, and two attended schools for "delicate" children.

The most severely disabled child was born in the second half of the study. She had cerebral palsy with moderate learning difficulties and a sensorineural hearing loss of $50 \mathrm{~dB}$.

\section{Discussion}

Within our district, the numbers of VLBW babies surviving after 1 month of age increased dramatically over the period of the study. This was the result of an improvement in the survival rate and an increase in the incidence of VLBW births. The fact that a greater number of notified live births was accompanied by a fall in mean birth weight for both survivors and neonatal deaths suggests that there was a change in notifications, rather than a true change in incidence. It seems likely that as the outlook for the VLBW baby improved, the management of preterm labour was more active, and smaller infants were resuscitated, notified as live births, and offered intensive care.

Despite the fact that the number of VLBW survivors had nearly doubled in the second half of the study, they did not make a greater contribution to the population of children with special educational needs in the district. For VLBW infants, the relative risk of SEN was lower in the second half of the study, but this was not statistically significant because of the small numbers involved.

The relative risk that VLBW infants would have subsequent special educational needs in this study ( 4.4 times more than normal birthweight infants) was similar to that in a Finnish study of the 1960 s $\left(3.5\right.$ times as likely). ${ }^{7}$ This increased risk of the need for special education may be the result of social as well as biological factors in the VLBW group. ${ }^{8}$

Table 3 Details of the neonatal course and educational problems of the six very low birthweight infants who were assessed for special educational needs. Neonatal characteristics are birth weight, gestational age $(G A)$, whether mechanical ventilation was given, and the main neonatal diagnoses $(P D A=$ patent ductus arteriosus; IUGR = intrauterine growth retardation; IVH=intraventricular haemorrhage). The nature of the problems at school age are shown, with the type of school placement after assessment for educational needs $(C P=$ cerebral palsy).

\begin{tabular}{|c|c|c|c|c|c|c|c|}
\hline \multirow[t]{2}{*}{ Period } & \multicolumn{4}{|c|}{ Neonatal characteristics } & \multicolumn{3}{|l|}{ Function at school age } \\
\hline & $\begin{array}{l}\text { Birthweight } \\
(g)\end{array}$ & $\begin{array}{l}G A \\
(w k)\end{array}$ & $\begin{array}{l}\text { Mechanical } \\
\text { vent }\end{array}$ & $\begin{array}{l}\text { Neonatal } \\
\text { diagnosis }\end{array}$ & $\begin{array}{l}\text { Physical } \\
\text { function }\end{array}$ & $\begin{array}{l}\text { Intellectual } \\
\text { function }\end{array}$ & $\begin{array}{l}\text { Type of school } \\
\text { placement }\end{array}$ \\
\hline \multirow[t]{3}{*}{$1974-77$} & 1220 & 30 & Yes & Prematurity, apnoea & Normal & \multirow{3}{*}{$\begin{array}{l}\text { Language delay, } \\
\text { general delay } \\
\text { Attention deficit, } \\
\text { patchy abilities } \\
\text { Normal }\end{array}$} & \multirow{2}{*}{$\begin{array}{l}\text { Moderate learning } \\
\text { difficulties } 1^{\circ} \& 2^{\circ} \\
\text { Delicate }\end{array}$} \\
\hline & 1420 & 32 & None & Prematurity & Normal & & \\
\hline & 1340 & 27 & None & PDA rickets & $\mathrm{CP}$ (ataxic diplegia) & & $\begin{array}{l}\text { Mainstream } 1^{\circ} \\
\text { physically handicapped } \\
2^{\circ}\end{array}$ \\
\hline \multirow[t]{3}{*}{$1977-80$} & 0950 & 31 & None & IUGR & Normal (asthma) & \multirow{2}{*}{$\begin{array}{l}\text { Language delay, mild } \\
\text { general delay } \\
\text { Normal }\end{array}$} & Delicate \\
\hline & 0880 & 28 & Yes & PDA bowel perforation & $\begin{array}{l}\text { CP (spastic diplegia), } \\
\text { visual acuity } 6 / 18\end{array}$ & & \multirow{2}{*}{$\begin{array}{l}\text { Mainstream } 1^{\circ} \text {, } \\
\text { mainstream/visually } \\
\text { impaired } 2^{\circ} \\
\text { Physical handicapped } \\
1^{\circ} / 2^{\circ}\end{array}$} \\
\hline & 1030 & 28 & Yes & $\begin{array}{l}\text { Klebsiella septicaemia, } \\
\text { IVH }\end{array}$ & $\begin{array}{l}\mathrm{CP} \text { (spastic diplegia), } \\
50 \mathrm{~dB} \text { hearing loss }\end{array}$ & $\begin{array}{l}\text { Moderate learning } \\
\text { difficulties }\end{array}$ & \\
\hline
\end{tabular}


We do not have complete ascertainment of handicap, since we do not have information about children whose special needs were recognised outside our district. Given our figures on residential stability, it is likely that the true risk of SEN is roughly twice that of our estimates. If those who stay are more likely to have SEN than those who move, then the true risk would be less than twice that of our estimates. This factor would apply equally to all birthweight groups, so that the relative risk figures would be reliable. However, it is possible that disabilities might be discovered earlier in children brought to the attention of medical services by their VLBW birth, and that this might lead parents to stay close to services with which they were familiar. If such children were less likely to move than larger children whose disability was discovered later, the estimate of relative risk for SEN in VLBW infants might be inflated.

One argument that is used against the provision of increased facilities for neonatal intensive care is that an increased "burden" arising from a greater number of handicapped children will have to be borne by the community. ${ }^{5} \mathrm{We}$ have not found this to be the case in the late 1970 s, in spite of a marked increase in VLBW survival in this period. The numbers of VLBW infants who went on to have SEN were small, limiting the accuracy of our conclusions. Nevertheless, the fact that their numbers were so small emphasises that even major increases in their survival may have little impact on overall patterns of disability in the school age population. ${ }^{9}$ Although the most severely disabled survivor was from the second half of the study period, there was no major difference in the type of educational provision required for the children from the two halves of the study.

Changing definitions of SEN and the recognition of a new spectrum of disabilities in VLBW survivors ${ }^{2}$ may lead to increasing numbers of such infants being assessed for SEN. Future studies of the contribution of VLBW infants to SEN should take account of the changing scope of the statementing process. Alternative measures of long term disability, such as the need for placement in a school for severe learning disability, are not likely to remain constant either, as increasing numbers of children with learning difficulties are integrated into mainstream education.

Rapid changes are occurring in the field of neonatal care, and today's survivors are smaller and sicker than those included in this study. As the scope of neonatal care includes lower gestations and birth weights, careful audit of outcome in distinct birthweight and gestational categories must continue. This constitutes an important tool which will help when deciding whether intensive care should be given to an individual baby. There was no evidence from the time period studied that increased survival of VLBW infants resulted in an increase in the total number of children with SEN in our community. The difficult decision of whether to offer intensive care to very small babies should continue to be made on the basis of the outlook for the individual baby, rather than on the basis of perceived effects on the community.

We would like to thank Lambeth, Southwark and Lewisham We would like to thank Lambeth, Southwark and Lewisham
Family Health Services Authority for their help in assessing the Family Health Services Authority for their help in assessing
residential stability of children of different birth weights.

1 Stewart AL, Reynolds EOR, Lipscomb AP. Outcome for infants of very low birthweight: survey of world literature. Lancet 1981;i:1038-41.

2 Ornstein M, Ohlsson A, Edmonds J, Asztalos E. Neonatal follow-up of very low birthweight/extremely low birthweight infants to school age: a critical overview. Acta paed Scand infants to school

3 Education Act 1981. London: HMSO

4 Powell TG, Pharoah POD, Cooke RWI. Survival and morbidity in a geographically defined population of very low birthweight infants. Lancet 1986; ; $539-43$.

5 Maddock CR. A population-based evaluation of sustained mechanical ventilation of newborn babies. Lancet 1987;ii: $1254-8$

6 Pharoah POD, Stevenson RC, Cooke RWI, Sandu B. Costs and benefits of neonatal intensive care. Arch Dis Child 1988; 63:715-8.

7 Rantakallio P, von Wendt L. Prognosis for low-birthweight infants up to the age of 14: a population study. Dev Med Ch Neurol 1985;27:655-63.

8 Cohen SE, Parmalee AH. Prediction of five-year StanfordBinet scores in preterm infants. Child Development 1983; 54:1242-53.

9 Alberman E, Benson J, McDonald A. Cerebral palsy and severe educational subnormality in low birth weight children: a comparison of births in 1951-53 and 1970-73. Lancet 1982;i:606-8. 